\title{
PREVALENCE OF HIGH-RISK BEHAVIOUR AMONG BLOOD DONORS AND PROPORTION OF SELF- DEFERRAL AFTER EDUCATION AMONG THOSE WITH HIGH-RISK BEHAVIOUR
}

\author{
Kala V. L1, Kumari K. C. Usha², Prema N. S3, Sajith V4, Mariya Baby ${ }^{5}$ \\ ${ }^{1}$ Assistant Professor, Department of Transfusion Medicine, Government Medical College, Kottayam. \\ ${ }^{2}$ Professor, Department of Transfusion Medicine, Sree Mookambika Institute of Medical Sciences, Kulasekharam. \\ ${ }^{3}$ Additional Professor, Department of Pathology, Government Medical College, Kollam. \\ ${ }^{4}$ Assistant Professor, Department of Transfusion Medicine, Government Medical College, Thrissur. \\ ${ }^{5}$ Counselor, Department of Transfusion Medicine, Government Medical College, Thiruvananthapuram.
}

\section{ABSTRACT}

\section{BACKGROUND}

Prevalence of infection, which can be transmitted by transfusion are increasing in the community. Even after the introduction of screening tests, the incidence of transfusion transmitted infections are still reported. The seronegative window can be closed to certain extent by educating and interviewing the donor.

This study is undertaken to analyse the high-risk behaviour among the donors and to find out the proportion of self-deferral of donors attending the Department of Transfusion Medicine, Medical College, Thiruvananthapuram.

\section{MATERIALS AND METHODS}

This is a prospective analysis of the donors attending the Department of Transfusion Medicine, Govt. Medical College, Thiruvananthapuram from November 2010 to January 2011, for having high-risk behaviour. Analysis of the prevalence of high-risk behaviour according to age, marital status and gender is done by making them fill a proforma and education was given to the donors to promote self-deferral. A hospital-based cross-sectional study was done. Statistical tests done were Chi square test and Z test for proportion.

\section{RESULTS}

In the study, 5184 apparently healthy donors between the age group of 18 and 60 years were studied during the period from November 2010 to January 2011. Among the 5184 donors, 639 (12.3\%) donors were admitted of having high-risk behaviour and $4545(87.7 \%)$ donors did not give any history of high-risk behaviour. Among the high-risk donors 39 (6.1\%) were alcoholics, 15 $(2.3 \%)$ were drug addicts, $90(14.1 \%)$ had the habit of chain smoking, $54(8.5 \%)$ had history of extramarital sex, 318 (49.8\%) had history of homosexuality and $366(57.3 \%)$ had history of pre-marital sex. Many of the donors had more than one risk factor. According to age wise classification in 18 - 30 years of age group, out of the $3213(62 \%)$ donors 390 (12\%) gave history of risk factors, 2823 (88\%) had no history of risk factor. In 31 - 40 age group, out of the total 1500 (28.9\%) donors 1314 (88\%) had negative history and $186(12 \%)$ gave positive history. Among the $450(8.6 \%)$ donors of 41 - 50 years' age group, 387 (86\%) gave negative history and $63(14.1 \%)$ gave positive history. In age group of 51 - 60 years out of the total $21(0.5 \%)$ donors none gave any history of risk factors. The age wise distribution of high-risk behaviour among donors were almost the same as in the distribution of donors according to age. There was no statistically significant variation in any of the age groups, $\mathrm{p}$ value $>0.05$. On gender wise analysis, only six females donated during the study period and one of them gave positive history for high-risk behaviour. Of the total 5184 donors, 2283 (44\%) of the donors were married and 2901 (56\%) were unmarried. Among the donors with positive history, $51.6 \%$ belonged to the married group and $48.4 \%$ belonged to the unmarried group. Donors with negative history, $43 \%$ belonged to married group and $57 \%$ to unmarried group. The positive history for risk factors were significantly high in the married group and significantly low in the unmarried group, p value $<0.01 ; 18$ - 30 years of age group showed total of 477 married donors, of which 369 (77\%) gave negative history and $108(22 \%)$ was with positive history which was significantly high. While in the unmarried group where a total of 2736 was analysed, 252 (90\%) gave negative history. A significantly lower number $282(10 \%)$ gave positive history. High risk behaviour was significantly high among the married group, p value $<0.014$. In $31-40$ age group, among the 1362 married donors positive risk factor was given by $159(12 \%)$ and negative by 1203 (88\%). Among the 138 unmarried donors, $111(80 \%)$ donors gave negative history and $27(20 \%)$ positive history. High risk donors were more in the unmarried group. This finding was statistically significant, $p$ value $<0.01$. Evaluating the 423 donors of $41-50$ years of age group, negative history was given by $360(85 \%)$ of married donors and $63(14 \%)$ gave positive history. Among the unmarried donors, all the $27(100 \%)$ gave negative history. This was statistically significant, p value $<0.01$. Of the donors of age group $51-60$ all were married and none gave a positive history. Since the proportion of self-deferral was high during the study period. Seropositivity among blood donors for the five transfusion transmitted infections in the study period showed a significant reduction. Among the 5814 donors during the study period, only 91 (1.76\%) were seropositive.

\section{CONCLUSION}

In the study, many admitted of having high-risk behaviour. Most of them admitted that they were not fit for donation. Few were of the opinion that they were fit to donate.

\section{KEYWORDS}

High-Risk Behaviour, Self-Deferral.

HOW TO CITE THIS ARTICLE: Kala VL, Usha KKC, Prema NS, et al. Prevalence of high-risk behaviour among blood donors and proportion of self-deferral after education among those with high-risk behaviour. J. Evolution Med. Dent. Sci. 2017;6(64):46564659, DOI: $10.14260 / \mathrm{Jemds} / 2017 / 1007$ 
Financial or Other, Competing Interest: None.

Submission 06-06-2017, Peer Review 27-07-2017,

Acceptance 03-08-2017, Published 10-08-2017.

Corresponding Author:

Dr. Kala V. L,

\#6A Cloud 9 Apartments,

Law College Road, Vanchiyoor P.O,

Thiruvananthapuram-695035,

Kerala, India.

E-mail: kilakish@yahoo.co.in

DOI: 10.14260/jemds/2017/1007

\section{(c) (i)}

\section{BACKGROUND}

Prevalence of infection, which can be transmitted by transfusion are increasing in the community.

Even after the introduction of screening tests, the incidence of transfusion transmitted infections are still reported. This is due to existence of window period, chronic carrier state and technical errors. Besides, it is impossible to do tests for all transfusion transmitted infections.

In risk reducing policies the three possibilities are zero risk, minimal risk and minimal risk at acceptable cost. As blood transfusion involves a biologic material collected from human source, it is impossible to provide zero risk. The seronegative window can be closed to certain extent by educating and interviewing the donor population before recruitment. It was observed that these procedures can reduce the prevalence of infection in first time blood donors by $80 \%$.

Transfusion safety study conducted at San Francisco showed transfusion transmitted HIV to rise rapidly from 1978 since its first occurrence to a peak risk of $1.1 \%$ in 1982. From 1983 onwards marked and progressive decline in seropositivity of donors was observed, which was attributable to awareness of infectious nature of HIV in the community and due to self-deferral and self-exclusion of the donors. Self-exclusion means excluding themselves if they know or think that their blood may be unsafe as a result of risk behaviour or because of the state of their own health. Self-deferral is postponing blood donation if there are temporary reasons for doing so. Behaviour deferrals are retained after test deployment as a layer of protection against false negative test results, test errors and erroneous component distribution.

The focus of efforts to increase the safety of blood supply that weighs heavily on screening needs to be shifted strongly to the selection, interview and the medical examination of the prospective donors. Safe donors are those who report no behavioural risk factors and whose donations are repeatedly seronegative for infectious agents.

Total donations in Kerala were 390000 in 2010 with a seropositivity of $1.1 \%$. The average donations per year in the Department of Transfusion Medicine, Government Medical College, Thiruvananthapuram is approximately 30,000 . On an average, 375 units of blood and blood products are released from this department every day.

This study is undertaken to analyse the high-risk behaviour among the donors and the proportion of selfdeferral of donors after education of those with high-risk behaviour attending the Department of Transfusion Medicine, Medical College, Thiruvananthapuram.

\section{MATERIALS AND METHODS}

A total number of 5184 apparently healthy prospective blood donors between age 18 - 60 years who donated during 2010 November - 2011 January were studied. A hospital-based cross-sectional study was done. Biodata of all donors were obtained with careful interview and providing a donor card. All blood donors were offered pre-donation counselling and were given a self-deferral proforma. They were allowed to conceal their identity while filling the proforma. Consent was obtained separately. Blood donors were given directions to self-defer or self-exclude if they think they belong to the highrisk group of donors, after writing the reason for the selfdeferral and handing over the proforma. Data from proforma was analysed for high-risk behaviour. Detailed analysis about the positive response to the questions about high-risk behaviour according to age, marital status and gender were done based on the proforma.

Criteria for exclusion of the donors included age less than 18 years or more than 60 years, body weight less than $50 \mathrm{~kg}$. Haemoglobin value less than $12.5 \mathrm{~g} / \mathrm{dL}$, recent history of ill health, blood transfusion, surgery, chronic disease or donation within 3 months. Data was coded entered, validated and analysed using statistical package for Social Science Version 11, statistical test done was chi square test and $\mathrm{Z}$ test for proportion.

\section{RESULTS}

In the study, 5184 apparently healthy donors between the age group of 18 and 60 years were studied during the period from November 2010 to January 2011. Among the 5184 donors, 639 donors admitted of having high-risk behaviour and 4545 donors did not give any history of high-risk behaviour.

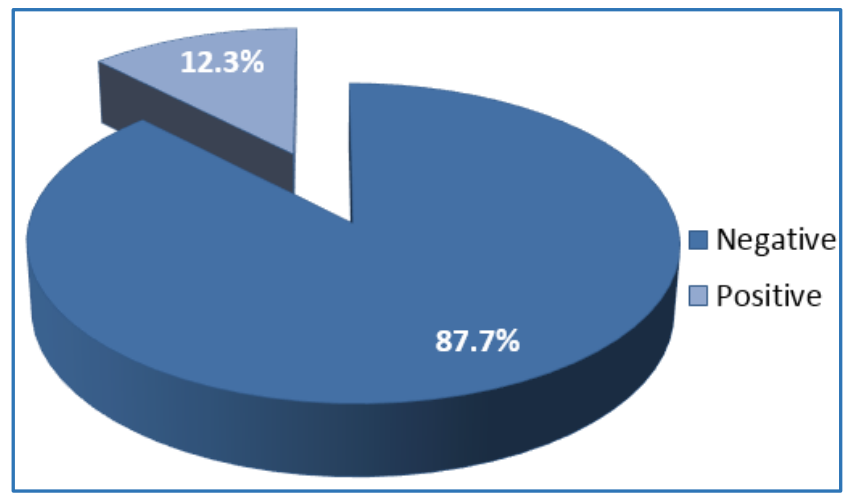

Figure 1. Percentage distribution of the Donors according to High-Risk Behaviour

\section{Analysis based on High-Risk Behaviour}

Among the high-risk donors 39 (6.1\%) were alcoholics, 15 $(2.3 \%)$ were drug addicts, $90(14.1 \%)$ had the habit of chain smoking, 54 (8.5\%) had history of extramarital sex, 318 (49.8\%) had history of homosexuality and 366 (57.3\%) had history of pre-marital sex. Many of the donors had more than one risk factor. 


\begin{tabular}{|c|c|c|}
\hline & Number & Percent \\
\hline Alcoholic & 39 & 6.1 \\
\hline Drug addict & 15 & 2.3 \\
\hline Smoking & 90 & 14.1 \\
\hline Extramarital sex & 54 & 8.5 \\
\hline Homosexuality & 318 & 49.8 \\
\hline Premarital sex & 366 & 57.3 \\
\hline \multicolumn{2}{|c|}{ Table 1. Percentage distribution of the } \\
Sample according to High-Risk Behaviour \\
\hline
\end{tabular}

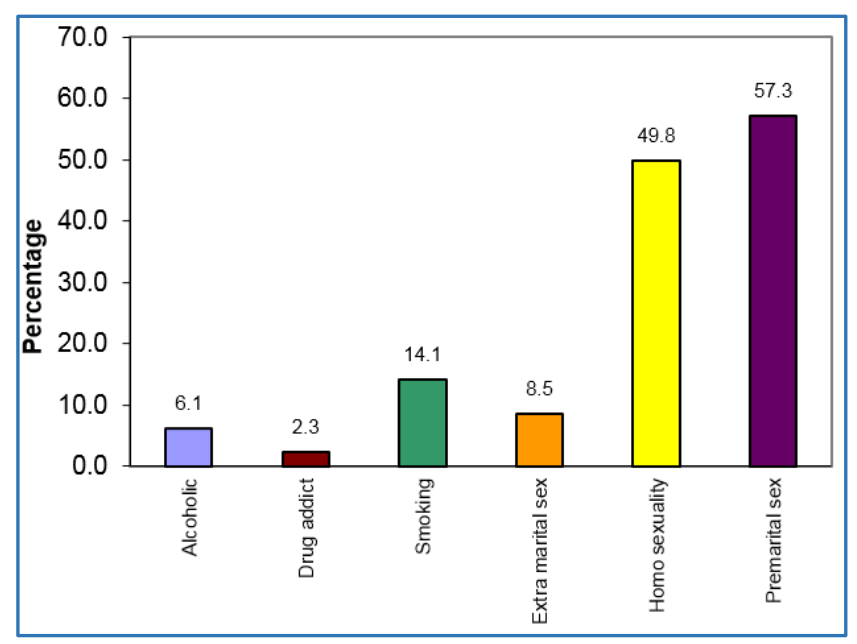

Figure 2. Percentage distribution of the Sample according to Selected Variables

\section{Analysis of Risk Behaviour according to Age}

According to age wise classification in 18 - 30 years of age group, out of the $3213(62 \%)$ donors $390(12 \%)$ gave history of risk factors which came up to $61 \%$ of total donors with positive history, 2823 (88\%) had no history of risk factor which was $62 \%$ of donors with negative history. In $31-40$ age group out of the total 1500 (28.9\%) donors 1314 (88\%) did not have any positive history, i.e. $28.9 \%$ of total donors with negative history; and $186(12 \%)$ gave positive history, i.e. $8.6 \%$ of total donors with positive history. Among the 450 (8.6\%) donors of 41 - 50 years' age group, 387 (86\%) gave negative history and $63(14.1 \%)$ gave positive history of risk factor that came upto $8.5 \%$ of total negatives and $9.9 \%$ of total positives. In age group of $51-60$ years, out of the total $21(0.5 \%)$ donors none gave any history of risk factors.

\begin{tabular}{|c|c|c|c|c|c|c|}
\hline \multirow{2}{*}{ Age } & Negative & \multicolumn{2}{c|}{ Positive } & \\
\cline { 2 - 7 } & Number & \% & Number & \% & Total & \% \\
\hline $18-30$ & 2823 & 62.1 & 390 & 61.0 & 3213 & 61.97 \\
\hline $31-40$ & 1314 & 28.9 & 186 & 29.1 & 1500 & 28.9 \\
\hline $41-50$ & 387 & 8.5 & 63 & 9.9 & 450 & 8.6 \\
\hline $51-60$ & 21 & 0.5 & 0 & 0.0 & 21 & 0.5 \\
\hline Total & $\mathbf{4 5 4 5}$ & $\mathbf{1 0 0 . 0}$ & $\mathbf{6 3 9}$ & $\mathbf{1 0 0 . 0}$ & $\mathbf{5 1 8 4}$ & $\mathbf{1 0 0}$ \\
\hline \multicolumn{7}{|c|}{ Table 2. Distribution of High-Risk } \\
Behaviour according to Age \\
\hline \\
$\chi^{2}=4.23, \mathrm{p}>0.05$
\end{tabular}

The age wise distribution of high-risk behaviour among donors was almost the same as in the distribution of donors according to age. There was no statistically significant variation in any of the age groups, $p$ value $>0.05$.
On gender wise analysis, only six females donated during the study period and one of them gave positive history for high-risk behaviour.

Of the total 5184 donors, 2283 (44\%) of the donors were married and 2901 (56\%) were unmarried.

According to the marital status among the total 2283 (44\%) married donors, 1953 (85.5\%) gave a negative history and $330(14.5 \%)$ gave a positive history. Among the 2901 (56\%) unmarried donors 2592 (88\%) gave a negative history and $309(12 \%)$ gave a positive history. Among the donors with positive history, $51.6 \%$ belonged to the married group and $48.4 \%$ belonged to the unmarried group. Donors with negative history, $43 \%$ belonged to married group and $57 \%$ to unmarried group. The positive history for risk factors were significantly high in the married group and significantly low in the unmarried group, $p$ value $<0.01$.

\begin{tabular}{|c|c|c|c|c|}
\hline \multirow{2}{*}{$\begin{array}{c}\text { Marital } \\
\text { Status }\end{array}$} & \multicolumn{2}{|c|}{ Negative } & \multicolumn{2}{c|}{ Positive } \\
\cline { 2 - 5 } Count & Percent & Count & Percent \\
\hline Married & 1953 & 43.0 & 330 & 51.6 \\
\hline Unmarried & 2592 & 57.0 & 309 & 48.4 \\
\hline Total & $\mathbf{4 5 4 5}$ & $\mathbf{1 0 0 . 0}$ & $\mathbf{6 3 9}$ & $\mathbf{1 0 0 . 0}$ \\
\hline \multicolumn{4}{|c|}{ Table 3. Distribution of Positivity } \\
according to Marital Status \\
\hline$\chi^{2=18.17, p<0.01}$
\end{tabular}

On analysing the donors of 18 - 30 years of age group showed total of 477 married donors, of which 369 (77\%) gave negative history and $108(22 \%)$ was with positive history which was significantly high. While in the unmarried group when a total of 2736 was analysed, 2524 (90\%) gave negative history and a significantly lower number 282 (10\%) gave positive history. High risk behaviour was significantly high among the married group, $\mathrm{p}$ value $<0.01$. Considering the 31 - 40 age group, among the 1362 married donors positive risk factor was given by $159(12 \%)$ and $1203(88 \%)$ married donors gave negative history of high-risk behaviour. Among the 138 unmarried, 111 (80\%) donors gave negative history and $27(20 \%)$ positive history. High risk donors were more in the unmarried group. This finding was statistically significant, $\mathrm{p}$ value $<0.01$.

In this study on evaluating the 423 donors of $41-50$ years of age group, negative history was given by $360(85 \%)$ of married donors and 63 (14\%) gave positive history. Among the unmarried donors, all the 27 (100\%) gave negative history. This was statistically significant, $\mathrm{p}$ value < 0.01 . Of the donors of age group $51-60$, all were married and none gave a positive history.

On comparison of the prevalence of seropositivity among blood donors for the five transfusion transmitted infections in the study period with the prevalence during the retrospective study period from 2007 - 2010, it was observed that there was a reduction in the seropositivity to almost half. Since the proportion of self-deferral was high during the study period. Out of 74280 donors studied retrospectively, 2601 (3.45\%) were seropositives and among the 5814 donors of the study period only 91 (1.76\%) were seropositive. There is a statistically significant reduction in the prevalence of seropositivity during the study period, $\mathrm{p}$ value $<0.01$. 


\section{DISCUSSION}

Blood donors belong to heterogeneous groups of people in the society differing in their demographic characteristics and the psychological factors that motivate their behaviour. ${ }^{1}$

The maximum number of donors were in the age group of 18 - 30 years were $62 \%$ followed by 31 - 40 years, i.e. $28.9 \%$. The donors of age group 41 - 50 was only $8.6 \%$ and above 51 - 60 years was $0.5 \%$.

The findings partly agree with previous study conducted in Nigeria, where majority of donors belonged to $20-29$ yrs. of age which was $44 \% .^{2}$ A contradicting report was obtained from Brazil where the maximum number of donor population was between 50 to 60 years of age. ${ }^{3}$

A total number of 5184 donors were analysed. The seropositivity among the donors during the study period was reduced to half $(1.76 \%)$ from that of previous year's $3.5 \%$.

Among the 639 donors who were admitted as having high-risk behaviour $6.9 \%$ were alcoholics, $2.3 \%$ were drug addicts, $14.1 \%$ had the habit of chain smoking, $8.5 \%$ admitted of extramarital sex, $49.8 \%$ gave history of homosexuality and $57.3 \%$ gave history of premarital sex.

Percentage of total donors (61.9\%) and percentage of donors who gave a history of high-risk behaviour (61.1\%) was almost the same for 18 - 30 age group. The percentage of high-risk donors was calculated from the total number of high-risk donors. Of the total donors, $28.9 \%$ were from 31 40 age group and $29.1 \%$ donors of high risk belonged to this age group donors; $9.9 \%$ of high-risk donors were from 41 50 age group, when $8.6 \%$ of total donors belonged to this group. Out of $21(0.5 \%)$ of donors who belonged to age group 51 - 60, none gave history of risk factors. The age wise distributions of high-risk behaviour among donors were almost the same as in the distribution of the donors according to age. Screening blood donors for high-risk behaviour and modification of practices like alcohol consumption have important public benefits.

When the marital status is considered among the total donors, $44 \%$ were married and $56 \%$ were unmarried. Unmarried donors included $57 \%$ of donors with negative history and $48.4 \%$ with positive history. Married group included $51.6 \%$ of donors with high-risk behaviour and $43 \%$ of donors with negative history. From the donors who gave a positive history of risk factors, $48.4 \%$ belonged to the unmarried group and $51.6 \%$ to the married group.

The history of positive risk factor was significantly high in the married than in the unmarried. It may be due to the fact that majority of the unmarried group are young students.

Considering the age wise analysis of high-risk behaviour among the married and unmarried donors. In the 18 - 30 age group, negative history was given by $86.9 \%$ of unmarried donors and $13.1 \%$ of married donors. In the donors with positive history, $72.3 \%$ were unmarried and $27.7 \%$ were married. Positive history was more among the married people. This was statistically significant, $\mathrm{p}$ value $<0.01$.

In 31 - 40 age group among donors with negative history, the distribution showed $91.6 \%$ of married and $8.4 \%$ unmarried. Among the donors with positive history, 85.5\% were married and $14.5 \%$ were unmarried. In this age group, positive history of risk factor was significantly high among the unmarried. P value $<0.01$. Considering the $41-50$ age group, $93 \%$ of donors with negative history belonged to the married group and $7 \%$ to the unmarried group. All the donors who gave positive history were married. The highrisk behaviour of the donors was significantly high among the married group, $\mathrm{p}$ value $<0.05$. Very few donors belonged to 51 - 60 age group. All were married and none gave history of high-risk behaviour. Very few females donated during the study period and only one gave history of high-risk behaviour.

In the study, most of the donors who admitted of having high-risk behaviour gave the answer yes for the question whether they were fit for donation. This can be due to two reasons. Either they could not comprehend about the infectivity of window period and transmission through transfusion of these infectious agents or they might be reluctant to leave the area without donation, since they did not want to make others aware that they were not fit for donation. They might have had pressure to donate from groups as peers, fellow employees and employers at work place or community blood drive (CUE).4,5 Response is in accordance with the study conducted in San Francisco. ${ }^{5}$ However, the decrease prevalence of seropositivity points to the fact that many having risk behaviour might have selfdeferred or self-excluded since they felt the privacy was adequate. - $^{-8}$

\section{CONCLUSION}

In the study, many admitted of having high-risk behaviour. Majority among them marked that they were fit to donate. However, the decrease in seroprevalence during the study period points to the fact that many having risk behaviour might have self-deferred or self-excluded. Computer interactive interview providing more privacy, CUE option and telephone call back option can further reduce the risk of transmission of infections through transfusion.

\section{REFERENCES}

[1] McMilan KD. President's page. Transfusion 1962;2:285.

[2] Menitove JE, Lewandowski C, Ashworth LW, et al. Confidential unit exclusion process continues to identify donors with an increased frequency of HIV seropositivity. Transfusion 1991;31:69S.

[3] Petersen LR, Lackriz E, Lewis WF, et al. The effectiveness of the confidential unit exclusion option. Transfusion 1994;34(10):865-9.

[4] Kessler D, Valinsky JE, Bianco C. Sensitivity and Specificity of confidential unit exclusion (CUE) - Does it work? Transfusion 1993;33:35S.

[5] Popovsky MA, McCarthy S, Schwab A. Dempessey- hart a: privacy of donor screening: perception vs reality. Transfusion 1991;31:67S.

[6] Silvergleid AJ, Leparc GF, Schmidt PJ. Impact of explicit questions about high risk activities on donor attitudes and donor deferral patterns. Results in two community blood centres. Transfusion 1989;29(4):362-4.

[7] Loiacono BR, Carter GR, Carter CS, et al. Efficacy of various methods of confidential unit exclusion in identifying potentially infectious blood donations. Transfution 1989;29(9):823-6.

[8] Wolles S, Galel S. Value of confidential unit exclusion. Transfusion 1993;33:80S. 